\title{
A NOVEL AUTOMATIC CALIBRATION SYSTEM FOR WATER VAPOR RAMAN LIDAR Giovanni Martucci ${ }^{1}$, Jordan Voirin ${ }^{1,2}$, Valentin Simeonov ${ }^{2}$, Ludovic Renaud ${ }^{1}$, and Alexander Haefele $^{1}$ \\ ${ }^{1}$ Federal Office of Meteorology and Climatology, MeteoSwiss, Payerne, Switzerland, *Giovanni.martucci@meteoswiss.ch \\ ${ }^{2}$ Ecole Polytechnique Fédérale de Lausanne - EPFL, CH-1015 Lausanne, Switzerland
}

\begin{abstract}
RALMO is operated at MeteoSwiss and provides continuous measurements of water vapor since 2008. Water vapor needs calibration to be used for climatological and meteorological studies. Primarily, RALMO is calibrated against a reference radiosonde. A secondary new calibration system based on an internal LED has been installed to perform automatic relative calibrations correcting for instrumental drifts. This study characterizes the secondary calibration system and validates it against the primary.
\end{abstract}

\section{INTRODUCTION}

The RAman Lidar for Meteorological Observations (RALMO) is operated at the Aerological station at Payerne $\left(46^{\circ} 480 \mathrm{~N}, 6^{\circ} 560\right.$ E, 491ma.s.1.) by Federal Office of Meteorology and Climatology MeteoSwiss in collaboration with the École Polytechnique Fédérale de Lausanne (EPFL) and provides continuous measurements of water vapor, temperature and aerosols almost uninterruptedly since 2008 [1],[2]. This long time series needs careful calibration to be used for climatological studies and operational meteorology. RALMO detects the Raman scattered light from atmospheric water vapor $\left(\mathrm{H}_{2} \mathrm{O}\right)$ and nitrogen $\left(\mathrm{N}_{2}\right)$, which allows to derive the water vapor mixing ratio $(\boldsymbol{\omega})$. The profiles of $\omega$ obtained by RALMO are calibrated using collocated radiosounding. The calibration factor obtained by scaling the $\omega$ profile obtained by RALMO to the $\omega$ profile from the radiosounding is corrected automatically by a system that accounts for the uneven aging $\left(f_{\text {aging }}\right)$ of the $\mathrm{N}_{2}$ and $\mathrm{H}_{2} \mathrm{O}$ photomultipliers. The expression for $\boldsymbol{\omega}$ can be obtained rearranging the terms in the LIDAR equation at each altitude $z$ for $\mathrm{H}_{2} \mathrm{O}$ and $\mathrm{N}_{2}$ :

$$
\omega(z)=C \frac{E_{H 2 O}(z)}{E_{N 2}(z)} \frac{T_{H 2 O}\left(z, \lambda_{H 2 O}\right)}{T_{N 2}\left(z, \lambda_{N 2}\right)}
$$

Where $E_{x}$ is the received energy, $\lambda_{x}$ is the Ramanshifted wavelength and $T_{x}$ is the atmospheric transmission at the Raman-shifted wavelengths. The factor $C$ is the system calibration factor and it depends on:

$$
C=\frac{\xi\left(\lambda_{N 2}\right) \gamma\left(\lambda_{N 2}\right) \sigma_{N 2}}{\xi\left(\lambda_{H 2 O}\right) \gamma\left(\lambda_{H 2 O}\right) \sigma_{H 2 O}}
$$

Where $\xi$ is the acquisition system's optical efficiency at the wavelength $\lambda, \gamma\left(\lambda_{x}\right)$ is the detectors' sensitivity and $\sigma_{\mathrm{x}}$ is the Ramanbackscattering cross section. The ratio of transmissions $T_{H 2 O}\left(z, \lambda_{H 2 O}\right) / T_{N 2}\left(z, \lambda_{N 2}\right)$ can be approximated to a constant value in the troposphere accounting for a departure of 5-10\% from unity due essentially to the unknown aerosol distribution [3].

\section{INSTRUMENT DESCRIPTION}

RALMO has been designed based on the following specifications: a narrow receiver's field of view; a narrowband grating polychromator that isolates the ro-vibrational Q-branches and high laser energy allowing to minimize the contamination by solar background and to maximize the signal-to-noise ratio; a near realtime data availability; long-term data consistency and system stability; autonomous operation; minimal maintenance and eye safety to ensure the possibility to measure without interfering with the surroundings. Such a system ensures high accuracy and precision of the measured parameters, the traceability of the measurement and high data availability since 2008. Table 1 summarizes the system parameters as it is described more in detail by Dinoev et al., 2013 [1]. RALMO laser's source emits at $1064 \mathrm{~nm}$ its fundamental harmonic, it then uses the third harmonic at $355 \mathrm{~nm}$ for measurements. A beam expander reduces the beam divergence at the instrument's output and the expanded beam is 
transmitted into the atmosphere. The light backscattered by the atmosphere is collected by the LIDAR's telescope (4 mirrors of $30 \mathrm{~cm}$ diameter) and transmitted by optical fibers separately to the $\mathrm{H}_{2} \mathrm{O}$ and Aerosol/Temperature polychromators for the wavelength separation. The photomultipliers detect the optical signals and convert them into electrical signals, which are acquired and stored for the data analysis.

Table 1 RALMO system parameters

\begin{tabular}{c|c}
\hline Transmitter & Receiver \\
Nd:YAG laser - third & Four fiber-coupled \\
parabolic mirrors: \\
Focal length: $1 \mathrm{~m}$ \\
Wavelength: $354.7 \mathrm{~nm}$ & Diameter: $0.3 \mathrm{~m}$ \\
Spectral line width: 0.7 & Axial displacement: \\
cm-1 & $235 \mathrm{~mm}$ \\
Rep. rate: $30 \mathrm{~Hz}$ & FOV: $3 \times 0.20 \mathrm{and} 1 \times 0.22$ \\
Pulse energy: $300 \mathrm{~mJ}$ & mrad \\
Pulse duration: $8 \mathrm{~ns}$ & Diffraction grating: \\
Beam expander - Galilean & Bandwidth (FWHM): 0.33 \\
type: & nm \\
Expansion ratio $15 \times$ & Central wavelength H2O \\
Transmitted beam: & 407.45 nm, N2 386.7 nm \\
Divergence: & Efficiency: 33\% (peak at \\
calculated $0.06 \mathrm{mrad}$ & H2O) \\
measured 0.09 $\pm 0.02 \mathrm{mrad}$ & Photodetectors \\
Diameter: $140 \mathrm{~mm}$ & (Hamamatsu) \\
& H2O R7600U-200 \\
& N2 and O2H6780 \\
\hline
\end{tabular}

\section{METHODOLOGY}

We define two types of calibration: the primary calibration ("external") made by collocated radiosounding and the secondary ("internal") made by an internal stabilized UV Light Emitting Diode (LED) source shining onto the $\mathrm{N}_{2}$ and $\mathrm{H}_{2} \mathrm{O}$ photomultipliers (PMTs). As a result of the external calibration, RALMO is scaled to the radiosounding $\omega$ profile and the calibration factor $C$ (eq.2) is obtained. The internal calibration system allows performing automatic relative corrections of $C$ that account for the differential aging $f_{\text {aging }}$ of the $\mathrm{N}_{2}$ and $\mathrm{H}_{2} \mathrm{O}$ PMTs. A single LED source is installed into the polychromator unit, shone onto the $\mathrm{N}_{2}$ and $\mathrm{H}_{2} \mathrm{O}$ PMTs and acquired by Licel acquisition system at $100 \mathrm{~Hz}$. The two PMTs are Hamamatsu photomultipliers: H6780-04 for the $\mathrm{N}_{2}$ signal and a R7600U-200 for the $\mathrm{H}_{2} \mathrm{O}$. The LED illuminates the same regions of the PMT's photocathodes that are illuminated by the atmospheric signal during normal measurements. This is essential for the accuracy of the calibration correction because of the high spatial inhomogeneity of the PMTs sensitivity [4]. The original design of the internal calibration procedure is provided by Simeonov et al., 2014, [5], here we provide a description of its latest development along with the main equations on which the method is based. The differential aging, $f_{\text {aging, }}$, causes a drift in the calibration factor in eq. 2 . Due to $f_{\text {aging, }}$ the true signal, $S_{\text {true }}$, of the atmospheric compound $X$, is not equal to the

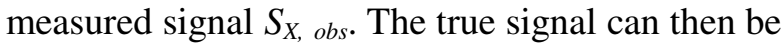
expressed as,

$$
S_{X, t r u e}(t)=f_{\text {aging }, X}(t) S_{X, o b s}(t)
$$

The equation 1 can be rewritten in the following way,

$$
\begin{gathered}
\boldsymbol{\omega}(t)=C \frac{S_{\mathrm{H}_{2} \mathrm{O}, \text { true }}(t)}{S_{N_{2}, \text { true }}(t)}= \\
C \frac{f_{\mathrm{H}_{2} \mathrm{O}}(t)}{f_{\mathrm{N}_{2}}(t)} \frac{S_{\mathrm{H}_{2} \mathrm{O}, \mathrm{obs}}(t)}{S_{N_{2}, o b s}(t)}=C_{\text {ext }}(t) \frac{S_{\mathrm{H}_{2} \mathrm{O}, \mathrm{obs}}(t)}{S_{N_{2}, o b s}(t)}
\end{gathered}
$$

$C_{e x t}$ is the calibration factor obtained by comparison with the radiosounding. If the two PMTs were aging at the same rate $\left(f_{\text {aging }}=1\right)$ then the ratio of their sensitivity would not change in time. The true LED signal ratio of $\mathrm{H}_{2} \mathrm{O} / \mathrm{N}_{2}$ must then be constant and can be written as,

$$
A_{L E D}=\frac{S_{\mathrm{H}_{2} O, L E D, t r u e}(t)}{S_{N_{2}, L E D, \text { true }}(t)}=\frac{f_{\mathrm{H}_{2} O}(t)}{f_{N_{2}}(t)} \frac{S_{\mathrm{H}_{2} O, L E D, o b s}(t)}{S_{N_{2}, L E D, o b s}(t)}
$$

By inversion of (5) the differential aging correction ratio is,

$$
\frac{f_{\mathrm{H}_{2} O}(t)}{f_{N_{2}}(t)}=A_{L E D} \frac{S_{N_{2}, L E D, o b s}(t)}{S_{H_{2} O, L E D, o b s}(t)}
$$

We can then rewrite the water vapor mixing ratio:

$$
\begin{aligned}
& \boldsymbol{\omega}(t)=C A_{L E D} \frac{S_{N_{2}, L E D, o b s}(t)}{S_{H_{2} O, L E D, o b s}(t)} \frac{S_{H_{2} O, o b s}(t)}{S_{N_{2}, o b s}(t)} \\
& =C^{\prime} \frac{S_{N_{2}, L E D, o b s}(t)}{S_{H_{2} O, L E D, o b s}(t)} \frac{S_{H_{2} O, o b s}(t)}{S_{N_{2}, o b s}(t)} \\
& =C^{\prime} r_{\text {aging }}(t) \frac{S_{H_{2} O, o b s}(t)}{S_{N_{2}, o b s}(t)}
\end{aligned}
$$

Comparing equations (4) and (7), at time zero, $t_{0}$,

$$
C^{\prime}=\frac{C_{\text {ext }}\left(t_{0}\right)}{r_{\text {aging }}\left(t_{0}\right)}
$$


Once the calibration factor is determined, we can calculate the water vapor mixing ratio at any time $t \geq t_{0}$,

$$
\boldsymbol{\omega}(t)=C_{\text {ext }}\left(t_{0}\right) \frac{r_{\text {aging }}(t)}{r_{\text {aging }}\left(t_{0}\right)} \frac{S_{H_{2} O, o b s}(t)}{S_{N_{2}, o b s}(t)}
$$

The corrected calibration factor, $C^{*}$, is then:

$$
C^{*}(t)=\frac{r_{\text {aging }}(t)}{r_{\text {aging }}\left(t_{0}\right)} C_{\text {ext }}\left(t_{0}\right)
$$

\section{RESULTS}

After having defined the corrected calibration factor, $C^{*}$, we validate the time series of $C^{*}(t)$ against the external calibration method. The validation consists of comparing eq.(10) with the external calibration factors $C_{e x t}\left(t_{\mathrm{i}}\right)$ at specific times $t_{\mathrm{i}}>t_{0}$. When the method based on eq. (10) is used operationally, the LIDAR profiles of $\omega$ are calibrated automatically. It is then important that, during the assessment phase, the time series $C^{*}(t)$ matches the reference values $C_{e x t}\left(t_{\mathrm{i}}\right)$. Figure 1 shows the comparison between the time series $C^{*}(t)$ (yellow) and the reference $C_{\text {ext }}\left(t_{\mathrm{i}}\right)$ values since July 2014 . The $C_{\text {ext }}\left(t_{\mathrm{i}}\right)$ values are obtained by calibration with different radiosondes: the operational SRS-C34 and SRS-C50 (black), the RS92 (red), the RS41 (blue) and the SnowWhite (green).

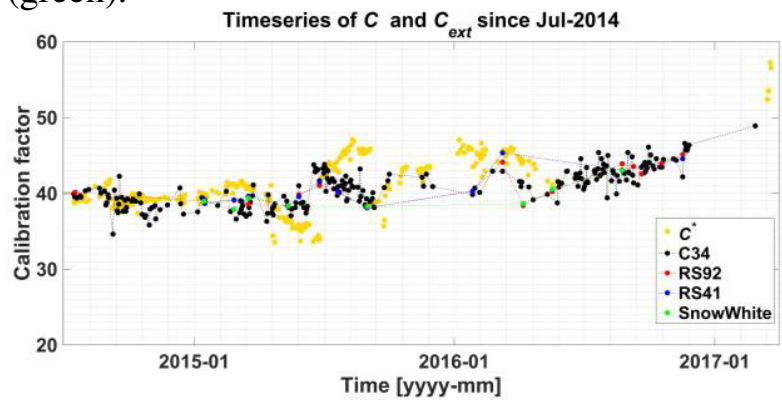

Figure 1 timeseries of the corrected calibration factor $C^{*}(t)$ (yellow) vs radiosounding $C_{\text {ext }}\left(t_{i}\right)$ calibrations based on LED ratio.

The timeseries of $C^{*}(t)$ does not match perfectly the timeseries of the $C_{e x t}\left(t_{i}\right)$ points. Especially during the year 2015 differences up to $20 \%$ can be observed between $C^{*}(t)$ and $C_{e x t}\left(t_{i}\right)$. In order to be a reference for $C^{*}(t)$, the $C_{e x t}\left(t_{i}\right)$ points must be determined accurately. The $C_{\text {ext }}\left(t_{i}\right)$ factors are obtained by selecting automatically the optimal vertical layers along the $\boldsymbol{\omega}$ profile where the agreement between RALMO and the radiosounding has a correlation coefficient $>0.6$. The selected optimal region (composed of multiple layers) is also a function of the distance of the radiosonde from RALMO and of the homogeneity of the atmosphere between the two. Figure 2 shows an example of automatic calibration with the selection of the optimal ranges in blue dots.

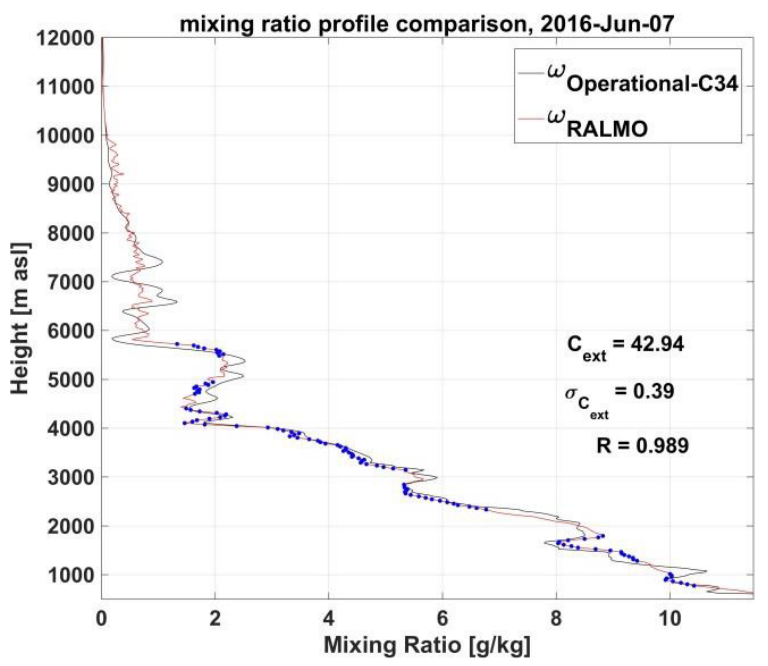

Figure 2 automatic selection of optimal region of $R A L M O$ vs $R S$.

All points respecting the condition $\mathrm{R}>0.6$ are linearly fitted and the slope of the fit gives the value of $C_{e x t}$. For the case shown in figure $C_{e x t}=$ 42.94, the correlation coefficient is $\mathrm{R}=0.99$ and the fit error is $1 \%$. Similar procedures to perform an automatic calibration based on external $\boldsymbol{\omega}$ profiles are described by [6],[7], [8]. Analyzing the $C^{*}(t)$ and $C_{e x t}\left(t_{i}\right)$ data in Figure 1, we cannot be satisfied with the reproducibility of the $C_{e x t}\left(t_{i}\right)$ points by the $C^{*}(t)$ timeseries. Different reasons can make the use of the internal calibration difficult, first of all the strong sensitivity of the internal calibration system to temperature changes along the optical path. It appears that small changes in the room temperature translate into changes of the incident angle of the LED light shining onto the PMT's leading to the variability of the $r_{\text {aging }}$ term. One way to avoid temperature dependencies of the automatic calibration system is to use the ratio of the solar background at the $\mathrm{N}_{2}$ and $\mathrm{H}_{2} \mathrm{O}$ wavelengths instead. The sun photons that travel towards RALMO are measured as a reference (same atmospheric path through the year) when the sun Zenith angle is at $20^{\circ}$, i.e. the maximum elevation angle on the 21st of 
December at Payerne. The solar background (BKG) ratio replaces the LED ratio in the above equations and the new $r_{\text {aging }}$ factor becomes:

$$
r_{\text {aging }}=\frac{\mathrm{S}_{\mathrm{N}_{2}, \mathrm{BKG}, \mathrm{obs}}(\mathrm{t})}{\mathrm{S}_{\mathrm{H}_{2} \mathrm{O}, \mathrm{BKG}, \mathrm{obs}}(\mathrm{t})}
$$

Using the BKG it allows to go back to the beginning of the data timeseries in 2008, while the LED data are available only since 2014 . The new timeseries of $C^{*}(t)$ based on BKG is shown in Figure 3.

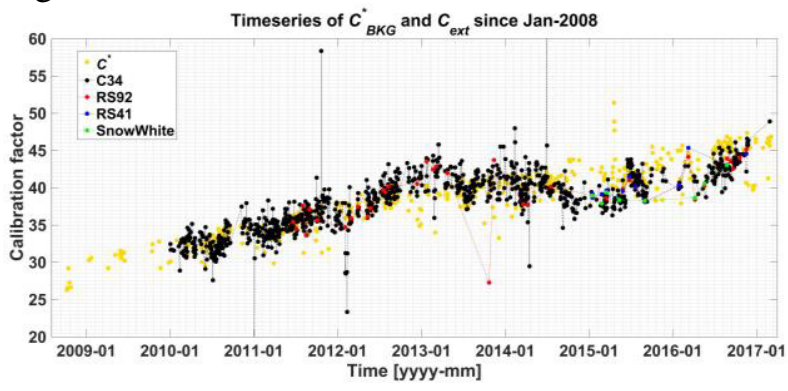

Figure 3 timeseries of the corrected calibration factor $C^{*}(t)$ (yellow) vs radiosounding $C_{\text {ext }}\left(t_{i}\right)$ calibrations based on BKG ratio.

\section{CONCLUSIONS}

An automatic procedure to calibrate the water vapor mixing ratio $(\boldsymbol{\omega})$ retrieved from RALMO has been developed and tested at the Aerological station of MeteoSwiss, Payerne. The method consists of the automatic correction of the calibration factor $C$ obtained by external calibration of RALMO $\boldsymbol{\omega}$ profile by comparison with radiosounding. The correction expressed by eq.(10) is based on an automatic monitoring of the differential aging of the $\mathrm{N}_{2}$ and $\mathrm{H}_{2} \mathrm{O}$ PMTs. Two different sources have been tested to calculate the differential aging of the PMTs: a LED (eq.6) and the solar background (eq.11). The $C^{*}$ values obtained using the LED showed a limited reproducibility of the $C_{e x t}$ factors, essentially due to temperature dependence of the calibration system. The $C^{*}$ values obtained using the BKG showed a better agreement with the $C_{e x t}$ factors and provided the possibility to extend the procedure over the entire RALMO datasets.

\section{ACKNOWLEDGEMENTS}

Dr. Shlomo Festig from Soreq Nuclear Research Center, Israel, has significantly contributed to the design and creation of the new internal calibration procedure.

\section{References}

[1] Dinoev, T., Simeonov, V., Arshinov, Y., Bobrovnikov, S., Ristori, P., Calpini, B., Parlange, M., and van den Bergh, H.: Raman Lidar for Meteorological Observations, RALMO - Part 1: Instrument description, Atmos. Meas. Tech., 6, 1329-1346, doi:10.5194/amt-6-1329-2013, 2013

[2] Brocard, E., Philipona, R., Haefele, A., Romanens, G., Ruffieux, D., Simeonov, V., and Calpini, B.: Raman Lidar for Meteorological Observations, RALMO - Part 2: Validation of water vapor measurements, Atmos. Meas. Tech.,6, 1347-1358, doi:10.5194/amt-6-13472013, 2013.

[3] Whiteman, D. N.: Raman lidar system for the measurement of water vapor and aerosols in the Earth's atmosphere, Appl. Opt., 31, 3068-3082, 1992.

[4] Simeonov V., Larcheveque G., Quaglia P., van den Bergh H., and Calpini B., "The influence of the PMT spatial uniformity on lidar signal," Appl.Opt, 38, 5186-5190 (1999).

[5] Simeonov V., Fastig S., Haefele A., and Calpini, B.: Instrumental correction of the uneven PMT aging effect on the calibration constant of a water vapor Raman lidar, Proc. SPIE 9246, Lidar Technologies, Techniques, and Measurements for Atmospheric Remote Sensing $\mathrm{X}, \quad 92460 \mathrm{~N} \quad$ (October 20, 2014); http://dx.doi.org/10.1117/12.2066802

[6] Dionisi, D., Congeduti, F., Liberti, G. L., and Cardillo, F.: Calibration of a Multichannel Water Vapor Raman Lidar through Noncollocated Operational Soundings: Optimization and Characterization of Accuracy and Variability, J. Atmos. Ocean. Tech., 27, 108-121, doi:10.1175/2009JTECHA1327.1, 2010.

[7] Foth, A., Baars, H., Di Girolamo, P., and Pospichal, B.: Water vapour profiles from Raman lidar automatically calibrated by microwave radiometer data during HOPE, Atmos. Chem. Phys., 15, 7753-7763, doi:10.5194/acp-15-7753-2015, 2015.

[8] Hicks, S., Sica, J. R., and Martucci, G.: Calibration of the MeteoSwiss RAman Lidar for Meteorological Observations (RALMO) Water Vapour Mixing Ratio Measurements using a Radiosonde Trajectory Method, contribution to ILRC28, Bucharest, 2017 